\title{
Isolated adrenocorticotropic hormone deficiency potentially induced by nivolumab following pseudo-progression in clear cell renal cell carcinoma: A case report
}

\author{
NOBUKI FURUBAYASHI, TAKAHITO NEGISHI, TOMOHARU UOZUMI, DAI TAKAMATSU, \\ KOICHI SHIRAISHI, DAISUKE HIROSE and MOTONOBU NAKAMURA \\ Department of Urology, National Kyushu Cancer Center, Fukuoka 811-1395, Japan
}

Received June 19, 2018; Accepted November 27, 2018

DOI: $10.3892 / \mathrm{mco} .2018 .1781$

\begin{abstract}
Nivolumab is a monoclonal immunoglobulin G antibody blocking programmed death receptor-1 (PD-1) that promotes the restoration of the natural T-cell-mediated immune response against cancer cells; however, it also causes a number of autoimmune-related adverse events (irAEs) that often involve the endocrine system. The present report describes a 71-year-old man with clear cell renal cell carcinoma metastasis in the lung. Following the 14th course of nivolumab therapy, the patient complained of general malaise, loss of appetite and mild consciousness disturbance. Laboratory tests revealed a severely elevated eosinophil ratio (26.2\%) and low sodium value $(122 \mathrm{mmol} / \mathrm{l})$. Endocrine system tests revealed that the patient's adrenocorticotropic hormone (ACTH; $4.5 \mathrm{pg} / \mathrm{ml}$ ) and cortisol $(0.1 \mu \mathrm{g} / \mathrm{dl})$ levels were lower than normal, while those of other pituitary hormones were higher than normal. This case was therefore diagnosed as isolated ACTH deficiency induced by nivolumab. Magnetic resonance imaging (MRI) showed normal pituitary glands. Hydrocortisone replacement therapy improved the clinical symptoms early and enabled the patient to restart nivolumab therapy. Isolated ACTH deficiency due to nivolumab, a PD-1 immune checkpoint inhibitor antibody, is a rare occurrence. This report may be useful for avoiding delays in the diagnosis and treatment of this life-threatening irAE even if no pituitary abnormalities are identified via MRI.
\end{abstract}

\section{Introduction}

Immune checkpoint inhibitors are breakthrough treatments for several malignancies. In November 2015, the United State

Correspondence to: Dr Nobuki Furubayashi, Department of Urology, National Kyushu Cancer Center, Notame 3-1-1, Minami-ku, Fukuoka 811-1395, Japan

E-mail: furubayashi.n@nk-cc.go.jp

Key words: clear cell renal cell carcinoma, nivolumab, programmed cell death protein-1, autoimmune-related adverse events, pseudo-progression
Food and Drug Administration approved nivolumab for renal cell carcinoma (RCC) patients who have previously undergone anti-angiogenic therapy, after showing a statistically significant and clinically meaningful difference in overall survival (1). In Japan, nivolumab has also been approved for use in the treatment of renal cell carcinoma since August 2016. Nivolumab is a programmed cell death protein-1 (PD-1) checkpoint inhibitor that selectively blocks the interaction between the PD-1 expressed on activated T-cells and its two ligands, programmed cell death ligand 1 (PD-L1) and PD-L2. By disrupting PD-1/PDL1 signaling, nivolumab is thought to restore the immune response and antitumor activity (2); however, it also increases the T-cell activity in normal tissues, and causes various immune-related adverse events (irAEs), which often involve the endocrine organs.

We herein report a case of a patient with renal cell carcinoma who developed isolated adrenocorticotropic hormone (ACTH) deficiency after pseudo-progression during nivolumab therapy.

\section{Case report}

Written consent was obtained from the patient. A 71-year-old Japanese man was referred to our hospital for the evaluation of a left renal tumor that had been detected by echography at a screening examination in June 2013. He had a history of hypertension and hypothyroidism. He was diagnosed with left renal cell carcinoma (cT3aNOM0) by computed tomography (CT) and underwent left kidney resection in July 2013.

Subsequently, single metastasis to the lung was observed, and surgical treatment was performed twice, with single metastases resected from the right and left lung in March 2014 and September 2014, respectively. However, multiple lung metastases were observed. Thus, treatment with molecular-targeted therapy was initiated in January 2015. Pazopanib was administered as the first-line therapy in January 2015, axitinib was administered as the second-line therapy from October 2015, and sunitinib was administered as the third-line therapy from May 2016. All of these drugs showed therapeutic efficacy, and resulted in stable disease, but had to be discontinued due to drug-induced adverse events.

The patient therefore began to receive nivolumab $(3 \mathrm{mg} / \mathrm{kg}$, intravenously) once every 2 weeks as the fourth-line therapy 
from May 2017 (Fig. 1A). CT revealed no new metastatic lesions, but the patient's lung metastases grew bigger, constituting progressive disease, after the 6th course of nivolumab therapy (Fig. 1B); however, because the patient had no adverse events, he decided to continue nivolumab therapy. After the 10th course of nivolumab, CT showed that the lung metastases had shrunk, and this case of 'efficacy after progression' was judged to have been evidence of pseudo-progression (Fig. 1C).

After the 14th course of nivolumab therapy in November 2017, he complained of general malaise, loss of appetite and mild consciousness disturbance. Although the disease condition was stable due to the administration of 3 molecular-targeted agents, the administration of these agents had to be discontinued due to adverse events. Thus, he consulted his primary care doctor because he did not believe that these symptoms were due to irAEs and was subsequently hospitalized without contacting our hospital (nivolumab therapy cycle 14, day 7). Cerebrovascular disease was suspected, and head magnetic resonance imaging (MRI) was performed, but no abnormal findings were observed, including in the pituitary gland (Fig. 2A and B). His consciousness disturbance deteriorated, and he became bedridden. Five days after hospitalization, our hospital was consulted about his condition (nivolumab therapy cycle 14, day 12). Initially, we considered performing emergency transportation to our hospital; however, due to his poor general condition, and the long distance between our institutions, we judged that his transfer would be difficult and instead asked for examinations and treatment to be performed at the primary care doctor's hospital.

His laboratory data showed a severely elevated eosinophil ratio $(26.2 \%)$ and low sodium value $(122 \mathrm{mmol} / \mathrm{l})$, while his potassium level was normal and his glucose level was high (Table I). Based on the clinical symptoms and examination values, ACTH deficiency was suspected, and the administration of hydrocortisone (100 mg/daily, intravenous) was immediately started as a diagnostic treatment.

Two days later, his condition dramatically improved, as his consciousness disorder was ameliorated and he began to eat meals again. The results of endocrine system tests revealed that his ACTH $(4.5 \mathrm{pg} / \mathrm{ml})$ and cortisol $(0.1 \mu \mathrm{g} / \mathrm{dl})$ levels were lower than normal. The levels of other anterior pituitary hormones [prolactin (PRL), luteinizing hormone ( $\mathrm{LH})$, follicle-stimulating hormone (FSH), thyroid-stimulating hormone (TSH)] were not low. Based on these findings, the diagnosis was isolated ACTH deficiency that was probably induced by nivolumab.

Three days later, the steroid treatment was changed to oral prednisolone (10 mg/day). Eight days later, a laboratory analysis showed that the patient's eosinophil ratio had dropped to $7.8 \%$, and his sodium value had improved to the reference range (140 mmol/l). Twenty-eight days later, he was transferred to our hospital on foot (nivolumab therapy cycle 14 day 28), and replacement therapy was initiated with hydrocortisone $20 \mathrm{mg} /$ day $\left(\right.$ Cortril $^{\circledR}$; morning $15 \mathrm{mg}$, evening $5 \mathrm{mg}$ ). After the 14th course of nivolumab therapy, CT showed that the lung metastases had shrunk in comparison to before treatment (Fig. 1D). On the 43rd day of the 14th course of nivolumab therapy, the 15 th course of nivolumab therapy was restarted. He currently received the 22th course of nivolumab therapy without complaining any clinical symptoms.

\section{Discussion}

Immunotherapy enhances a patient's immune system to fight disease and has recently been identified as a promising new cancer treatment (3). Among these immunotherapeutic strategies, immune checkpoint blockade increases antitumor immunity by blocking intrinsic downregulators of immunity, such as cytotoxic T-lymphocyte antigen-4 (CTLA-4) and PD-1 or its ligand, PD-L1. Several immune checkpoint-directed antibodies have been shown to improve overall survival for a number of advanced malignancies (4-6). Nivolumab, a PD-1 antibody, is widely used for the treatment of malignant melanoma (5), non-small cell lung cancer (7), renal cell carcinoma (8), head and neck carcinoma (9), Hodgkin's lymphoma (10) and gastric cancer (11). However, because immune-checkpoint blockade increases the immune system activity, it can have inflammatory side effects, which are often referred to as irAEs. Although any organ system can be affected, irAEs most commonly involve the gastrointestinal tract, endocrine glands, skin and liver (12). These types of adverse events are specific for immune checkpoint-blocking antibodies and rare in the era of molecular-targeted therapy.

We herein report a case of isolated ACTH deficiency that was probably induced by an autoimmune-related mechanism caused by nivolumab after pseudo-progression in renal cell carcinoma. Hypophysitis is more common in immune checkpoint blockade with CTLA4 antibodies, such as ipilimumab, which is associated with an incidence rate of $9.1 \%$ (13). In contrast, nivolumab-associated all-grade pituitary dysfunction only occurred in $0.5-0.9 \%$ of reported cases $(5,6,14-19)$. At most hospitals, takes a few days to obtain the results of endocrine system examinations. Furthermore, clinical symptoms such as general malaise, loss of appetite and mild consciousness disturbance are often seen in patients with malignant diseases, which hampers the diagnosis of irAEs.

Imaging examinations can alternatively be used to obtain a diagnosis. For example, in cases of hypophysitis, the enlargement of the pituitary gland (up to $60-100 \%$ of the baseline size) with thickening of the stalk can be seen on MRI (20). Enlargement of the pituitary gland is reported to occur in all cases of anti-CTLA4 antibody-induced hypophysitis (21). However, in the present case, the isolated ACTH deficiency appeared to have been caused by nivolumab and occurred without pituitary gland enlargement. Similar cases of nivolumab-induced isolated ACTH deficiency without pituitary gland enlargement have also been reported (22-25). The nivolumab-induced cases took much longer to diagnose than ipilimumab-induced cases (26). Our patient was treated with 14 courses of nivolumab over a 7-month period. Given the time until the diagnosis and the radiographic characteristics, the inflammation in the pituitary gland due to nivolumab-induced hypophysitis may not have been more severe than the inflammation in the pituitary gland due to ipilimumab-induced hypophysitis. Caturegli et al (27) performed an autopsy analysis of the pituitary glands of patients with cancer treated by CTLA-4 blockade and reported that higher expression of CTLA-4 in the pituitary gland was related to more severe hypophysitis based on a type II or type IV allergy to anti-CTLA-4 antibodies. To the best of our knowledge, there have been no reports on the pathogenesis of nivolumab-induced hypophysitis. 


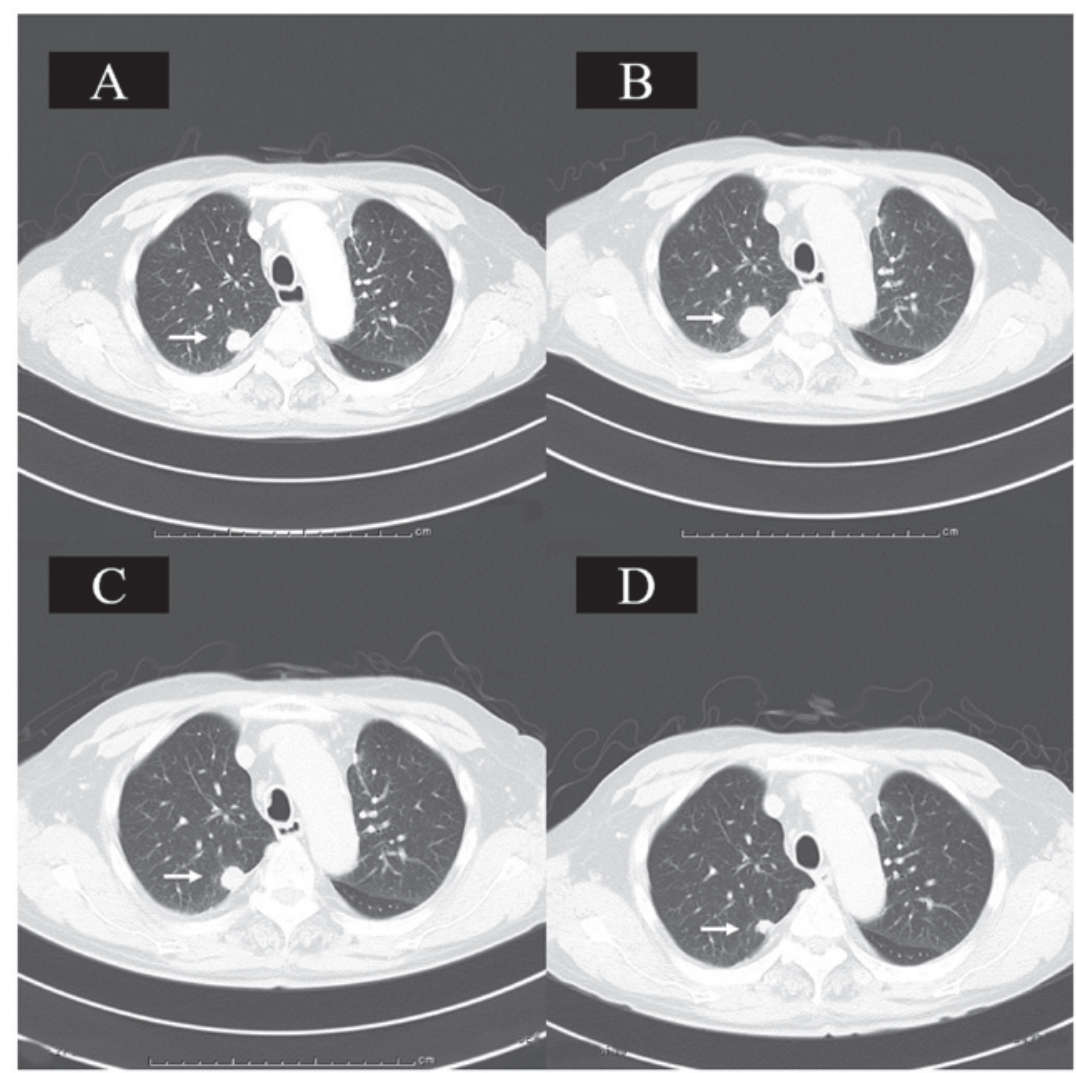

Figure 1. Chest CT. (A) Chest CT revealed a metastatic lung tumor in the right upper lobe prior to nivolumab therapy. (B) Following the 6th course of nivolumab therapy, CT revealed that the lung metastases had grown, representing progressive disease. (C) Following the 10th course of nivolumab therapy, CT demonstrated that the lung metastases had shrunk to their pretreatment size. (D) Following the 14th course of nivolumab therapy, CT showed that the lung metastases had shrunk when compared with that observed prior to treatment. Arrows indicate the area of lung metastasis. CT, computed tomography.

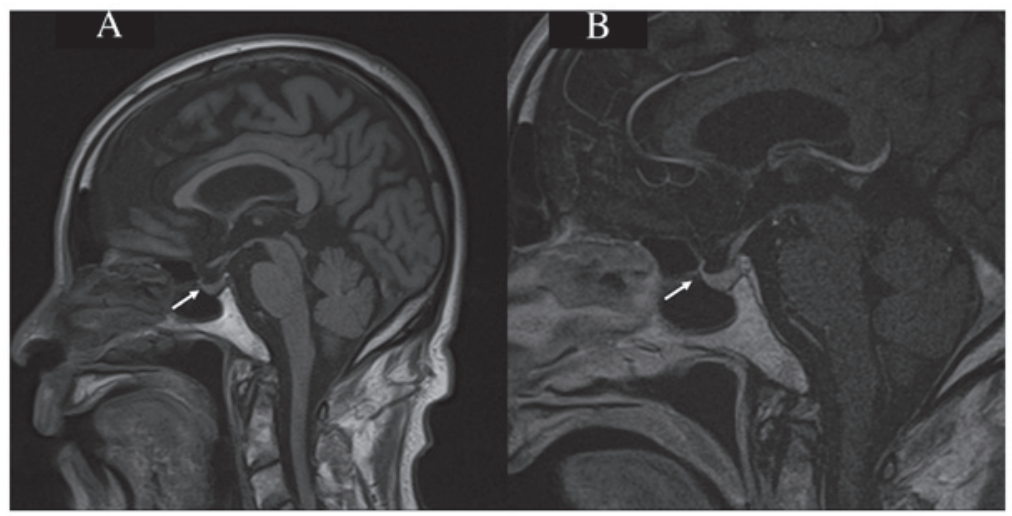

Figure 2. Brain MRI. (A) A sagittal section of a T1-weighted brain MRI scan revealed no enlargement of the pituitary gland or thickening of the stalk (arrow). (B) A sagittal section of a contrast-enhanced T1-weighted MRI scan revealed no abnormality in the pituitary gland (arrow). MRI, magnetic resonance imaging.

We are urologists and fortunately have experience in the treatment of adrenal insufficiency. Thus, we were able to diagnose the patient and start treatment based on the patient's symptoms and general laboratory data without waiting for the results of the endocrine examination. These case reports, including our own, may be useful for avoiding delays in the diagnosis and treatment of this life-threatening irAE, even without findings of pituitary abnormalities on MRI. Hypophysitis is well known to cause isolated ACTH deficiency by an autoimmune-related mechanism (28). While a rapid ACTH test should have been carried out for a definitive diagnosis (29), the duration from the onset of symptoms to the diagnosis was extremely long; thus, diagnostic treatment was prioritized. The endocrine system tests revealed that among the anterior pituitary hormones, only the levels of ACTH were lower than normal, with the levels of other anterior pituitary hormones, such as PRL, LH, FS and TSH, being higher than normal; furthermore, the cortisol levels were also lower than normal. Thus, this case was diagnosed as isolated ACTH deficiency induced by nivolumab, and hydrocortisone $\left(\right.$ Cortril $\left.^{\circledR}\right)$ was continuously administered according to the Japan Endocrine Society 
Table I. Laboratory data of the male patient.

\begin{tabular}{|c|c|c|c|c|c|}
\hline Laboratory data & Reference value & C14D12 & C14D20 & C14D29 & C14D42 \\
\hline WBC, n & $3,300-8,600 / \mu 1$ & 7,800 & 13,400 & 10,490 & 8,990 \\
\hline Eosino $(\%)$ & $1.0-6.0$ & 26.2 & 7.8 & 8.6 & 8.1 \\
\hline $\mathrm{Na}, \mathrm{mmol} / 1$ & $138-145$ & 122 & 140 & 141 & 143 \\
\hline $\mathrm{K}, \mathrm{mmol} / \mathrm{l}$ & $3.6-4.8$ & 3.8 & 4.4 & 4.0 & 3.7 \\
\hline Glu, mg/dl & 73-109 & 153 & 88 & 92 & 98 \\
\hline PRL, ng/ml & $4.29-13.69$ & 360.6 & & 253.2 & \\
\hline $\mathrm{LH}, \mathrm{mIU} / \mathrm{ml}$ & $0.79-5.72$ & 7.5 & & 10.36 & \\
\hline $\mathrm{FSH}, \mathrm{mIU} / \mathrm{ml}$ & $2.00-8.30$ & 13.88 & & 19.71 & \\
\hline $\mathrm{TSH}, \mu \mathrm{IU} / \mathrm{ml}$ & $0.49-4.67$ & 38.57 & 19.16 & 6.1 & \\
\hline F-T4, ng/dl & $0.71-1.85$ & 1.06 & 1.26 & 0.90 & \\
\hline $\mathrm{ACTH}, \mathrm{pg} / \mathrm{ml}$ & $7.2-63.3$ & 4.5 & & 4.9 & 2.1 \\
\hline Aldosterone, $\mathrm{pg} / \mathrm{ml}$ & $35.7-240$ & 90.9 & & & \\
\hline Cortisol, $\mu \mathrm{g} / \mathrm{dl}$ & $6.24-18.0$ & 0.1 & 0.44 & 0.29 & 31.10 \\
\hline Testosterone, $\mathrm{ng} / \mathrm{ml}$ & $1.31-8.71$ & 4.19 & & 2.07 & \\
\hline
\end{tabular}

WBC, white blood cell; PRL, prolactin; LH, luteinizing hormone; FSH, follicle-stimulating hormone; TSH, thyroid-stimulating hormone; F-T4, thyroxine; ACTH, adrenocorticotropic hormone; Eosino, eosinophil ratio; C14, cycle 14; D, day.

clinical practice guidelines (29). The temporarily high TSH value was considered to be due to the combination of the following three factors: The possible insufficiency of the thyroid drugs for primary hypothyroidism, decreased conversion to free triiodothyronine as a biological reaction due to the deterioration of general condition, and adrenocortical hypofunction.

When we encountered this patient, nivolumab was recommended as the treatment after antiangiogenic therapy based on the results of the CheckMate 025 study (8). Given that our patient had been experiencing various adverse events associated with molecular-targeted drugs, he considered the clinical symptoms that occurred at the time to be similar to previously experienced symptoms. Consequently, his presentation to our hospital was delayed, which necessarily delayed the diagnosis and treatment. This case highlights the importance of patient education. Since our experience in treating this patient, we have strengthened our approach to patient education regarding adverse events when introducing nivolumab. The European Association of Urology guidelines have already been updated based on the results of the phase III Checkmate-214 clinical trial $(30,31)$. That trial showed that the combination of nivolumab and ipilimumab in treatment-naïve patients with clear-cell metastatic renal cell carcinoma of intermediate and poor risk (classified by the International Metastatic Renal Cell Carcinoma Database Consortium) leads to superior survival in comparison to sunitinib. This treatment regimen will soon be approved in Japan, which will necessitate further caution. Immune check-point inhibitors are relatively new therapeutic agents, so our experience with their associated irAEs remains insufficient. Because physicians have few opportunities to experience cases different irAEs individually, the diagnosis and treatment of these events can be facilitated by the publication of detailed clinical case reports.
We reported a case of adrenal insufficiency that was probably induced by nivolumab after pseudo-progression. In this case-in contrast to most autoimmune hypophysitis cases that can typically be diagnosed by MRI-the pituitary gland showed no enlargement. The careful observation of a patient's clinical symptoms without resorting to imaging examinations enables the effective treatment at an earlier point in the clinical course.

\section{Acknowledgements}

Not applicable.

\section{Funding}

No funding was received.

\section{Availability of data and materials}

All data generated or analyzed during this study are included in this published article.

\section{Authors' contributions}

NF and TN participated in the conception and design of the case report, analyzed and interpreted the data and wrote the manuscript. TU, DT, KS and DH evaluated the patient and participated in the therapy. TU and MN evaluated radiological images. TN and $\mathrm{MN}$ supervised the study and critically reviewed the manuscript for important intellectual content. All authors have read and approved the final version of the manuscript.

\section{Ethics approval and consent to participate}

The present case report was approved by the Institutional Review Board of National Kyushu Cancer Center (Fukuoka, 
Japan), and written informed consent was obtained from the patient.

\section{Patient consent for publication}

The patient provided written informed consent for the publication of any associated data and accompanying images.

\section{Competing interests}

The authors declare that they have no competing interests.

\section{References}

1. Xu JX, Maher VE, Zhang L, Tang S, Sridhara R, Ibrahim A, Kim G and Pazdur R: FDA approval summary: Nivolumab in advanced renal cell carcinoma after anti-angiogenic therapy and exploratory predictive biomarker analysis. Oncologist 22: 311-317, 2017.

2. Gianchecchi E, Delfino DV and Fierabracci A: Recent insights into the role of the PD-1/PD-L1 pathway in immunological tolerance and autoimmunity. Autoimmun Rev 12: 1091-1100, 2013.

3. Postow MA, Sidlow R and Hellmann MD: Immune-related adverse events associated with immune checkpoint blockade. $\mathrm{N}$ Engl J Med 378: 158-168, 2018.

4. Hodi FS, O'Day SJ, McDermott DF, Weber RW, Sosman JA, Haanen JB, Gonzalez R, Robert C, Schadendorf D, Hassel JC, et al: Improved survival with ipilimumab in patients with metastatic melanoma. N Engl J Med 363: 711-723, 2010

5. Robert C, Long GV, Brady B, Dutriaux C, Maio M, Mortier L, Hassel JC, Rutkowski P, McNeil C, Kalinka-Warzocha E, et al: Nivolumab in previously untreated melanoma without BRAF mutation. N Engl J Med 372: 320-330, 2015.

6. Weber JS, D'Angelo SP, Minor D, Hodi FS, Gutzmer R, Neyns B, Hoeller C, Khushalani NI, Miller WH Jr, Lao CD, et al: Nivolumab versus chemotherapy in patients with advanced melanoma who progressed after anti-CTLA-4 treatment (CheckMate 037): A randomised, controlled, open-label, phase 3 trial. Lancet Oncol 16: 375-384, 2015.

7. Borghaei H, Paz-Ares L, Horn L, Spigel DR, Steins M, Ready NE, Chow LQ, Vokes EE, Felip E, Holgado E, et al: Nivolumab versus docetaxel in advanced nonsquamous non-small-cell lung cancer. N Engl J Med 373: 1627-1639, 2015.

8. Motzer RJ, Escudier B, McDermott DF, George S, Hammers HJ, Srinivas S, Tykodi SS, Sosman JA, Procopio G, Plimack ER, et al: Nivolumab versus everolimus in advanced renal-cell carcinoma. N Engl J Med 373: 1803-1813, 2015.

9. Ferris RL, Blumenschein G Jr, Fayette J, Guigay J, Colevas AD, Licitra L, Harrington K, Kasper S, Vokes EE, Even C, et al: Nivolumab for recurrent squamous-cell carcinoma of the head and neck. N Engl J Med 375: 1856-1867, 2016.

10. Younes A, Santoro A, Shipp M, Zinzani PL, Timmerman JM, Ansell S, Armand P, Fanale M, Ratanatharathorn V, Kuruvilla J, et al: Nivolumab for classical Hodgkin's lymphoma after failure of both autologous stem-cell transplantation and brentuximab vedotin: A multicentre, multicohort, single-arm phase 2 trial. Lancet Oncol 17: 1283-1294, 2016.

11. Kang YK, Boku N, Satoh T, Ryu MH, Chao Y, Kato K, Chung HC, Chen JS, Muro K, Kang WK, et al: Nivolumab in patients with advanced gastric or gastro-oesophageal junction cancer refractory to, or intolerant of, at least two previous chemotherapy regimens (ONO-4538-12, ATTRACTION-2): A randomised, double-blind, placebo-controlled, phase 3 trial. Lancet 390: 2461-2471, 2017.

12. Weber JS, Hodi FS, Wolchok JD, Topalian SL, Schadendorf D, Larkin J, Sznol M, Long GV, Li H, Waxman IM, et al: Safety profile of nivolumab monotherapy: A pooled analysis of patients with advanced melanoma. J Clin Oncol 35: 785-792, 2017.

13. Byun DJ, Wolchok JD, Rosenberg LM and Girotra M: Cancer immunotherapy-immune checkpoint blockade and associated endocrinopathies. Nat Rev Endocrinol 13: 195-207, 2017.

14. Naidoo J, Page DB, Li BT, Connell LC, Schindler K, Lacouture ME, Postow MA and Wolchok JD: Toxicities of the anti-PD-1 and anti-PD-L1 immune checkpoint antibodies. Ann Oncol 26: 2375-2391, 2015.
15. Topalian SL, Hodi FS, Brahmer JR, Gettinger SN, Smith DC, McDermott DF, Powderly JD, Carvajal RD, Sosman JA, Atkins MB, et al: Safety, activity, and immune correlates of anti-PD-1 antibody in cancer. N Engl J Med 366: 2443-2454, 2012.

16. Brahmer J, Reckamp KL, Baas P, Crinò L, Eberhardt WE, Poddubskaya E, Antonia S, Pluzanski A, Vokes EE, Holgado E, et al: Nivolumab versus docetaxel in advanced squamous-cell non-small-cell lung cancer. N Engl J Med 373: 123-135, 2015.

17. Gettinger SN, Horn L, Gandhi L, Spigel DR, Antonia SJ, Rizvi NA, Powderly JD, Heist RS, Carvajal RD, Jackman DM, et al: Overall survival and long-term safety of nivolumab (Anti-Programmed Death 1 Antibody, BMS-936558, ONO-4538) in patients with previously treated advanced non-small-cell lung cancer. J Clin Oncol 33: 2004-2012, 2015.

18. Motzer RJ, Rini BI, McDermott DF, Redman BG, Kuzel TM, Harrison MR, Vaishampayan UN, Drabkin HA, George S, Logan TF, et al: Nivolumab for metastatic renal cell carcinoma: Results of a randomized phase II trial. J Clin Oncol 33: 1430-1437, 2015.

19. Rizvi NA, Mazières J, Planchard D, Stinchcombe TE, Dy GK, Antonia SJ, Horn L, Lena H, Minenza E, Mennecier, B et al: Activity and safety of nivolumab, an anti-PD-1 immune checkpoint inhibitor, for patients with advanced, refractory squamous non-small-cell lung cancer (CheckMate 063): A phase 2, single-arm trial. Lancet Oncol 16: 257-265, 2015.

20. Blansfield JA, Beck KE, Tran K, Yang JC, Hughes MS, Kammula US, Royal RE, Topalian SL, Haworth LR, Levy C, et al: Cytotoxic T-lymphocyte-associated antigen-4 blockage can induce autoimmune hypophysitis in patients with metastatic melanoma and renal cancer. J Immunother 28: 593-598, 2005.

21. Ryder M, Callahan M, Postow MA, Wolchok J and Fagin JA: Endocrine-related adverse events following ipilimumab in patients with advanced melanoma: A comprehensive retrospective review from a single institution. Endocr Relat Cancer 21: 371-381, 2014.

22. Ishikawa M and Oashi K: Case of hypophysitis caused by nivolumab. J Dermatol 44: 109-110, 2017.

23. Fujimura T, Kambayashi Y, Furudate S, Kakizaki A, Hidaka T, Haga T, Hashimoto A, Morimoto R and Aiba S: Isolated adrenocorticotropic hormone deficiency possibly caused by nivolumab in a metastatic melanoma patient. J Dermatol 44: e13-e14, 2017.

24. Kitajima K, Ashida K, Wada N, Suetsugu R, Takeichi Y, Sakamoto S, Uchi H, Matsushima T, Shiratsuchi M, Ohnaka K, et al: Isolated ACTH deficiency probably induced by autoimmune-related mechanism evoked with nivolumab. Jpn J Clin Oncol 47: 463-466, 2017.

25. Takaya K, Sonoda M, Fuchigami A and Hiyoshi T: Isolated adrenocorticotropic hormone deficiency caused by nivolumab in a patient with metastatic lung cancer. Intern Med 56: 2463-2469, 2017.

26. Faje A: Immunotherapy and hypophysitis: Clinical presentation, treatment, and biologic insights. Pituitary 19: 82-92, 2016.

27. Caturegli P, Di Dalmazi G, Lombardi M, Grosso F, Larman HB, Larman T, Taverna G, Cosottini M and Lupi I: Hypophysitis secondary to cytotoxic T-lymphocyte-associated protein 4 blockade: Insights into pathogenesis from an autopsy series. Am J Pathol 186: 3225-3235, 2016.

28. Caturegli P, Newschaffer C, Olivi A, Pomper MG, Burger PC and Rose NR: Autoimmune hypophysitis. Endocr Rev 26: 599-614, 2005.

29. Yanase T, Tajima T, Katabami T, Iwasaki Y, Tanahashi Y, Sugawara A, Hasegawa T, Mune T, Oki Y, Nakagawa Y, et al: Diagnosis and treatment of adrenal insufficiency including adrenal crisis: A Japan Endocrine Society clinical practice guideline [Opinion]. Endocr J 63: 765-784, 2016.

30. Powles T, Albiges L, Staehler M, Bensalah K, Dabestani S, Giles RH, Hofmann F, Hora M, Kuczyk MA, Lam TB, et al: Updated European association of urology guidelines recommendations for the treatment of first-line metastatic clear cell renal cancer. Eur Urol: Dec 7, 2017 (Epub ahead of print).

31. Motzer RJ, Tannir NM, McDermott DF, Arén Frontera O, Melichar B, Choueiri TK, Plimack ER, Barthélémy P, Porta C, George S, et al: Nivolumab plus ipilimumab versus sunitinib in advanced renal-cell carcinoma. N Engl J Med 378: 1277-1290, 2018. 